\title{
EDITORIAL: ENDOTHELIAL AND MYOCARDIAL STUNNING
}

Gerald D. Buckberg, MD

U

ntil recently, myocyte stunning from inadequate cardiac protection has been the main focus of interest and is most relevant in damaged hearts (ie, hypertrophy, unstable angina, and reduced ejection fraction) in which vulnerability is accentuated. This injury is transient, since stunning recovers after brief inotropic or mechanical support. This editorial focuses on an expanding recognition that both the myocyte and the endothelium can be injured or stunned, as the two limbs are interrelated.

Damaged hearts exhibit loss of endothelium-dependent factors and reduced nitric oxide formation. The result is perioperative vasospasm, adherence of platelets, and leukocyte attachment that also causes capillary obstruction with inhomogeneous flow. The essential theme is that the endothelium is injured, because neutrophils do not attach, then roll, and finally have parenchymal influence for oxygen radical injury without such damage. This clinical report is the application of an experimentally proven method to reduce the consequences of endothelial damage.

The transient nature of stunning is clear. Brief leukocyte depletion (ie, > 95\% white blood cell reduction in this study) is quickly reversed by blood with a normal white cell count. However, the persistence of functional benefits indicates that residual protection is retained, including experimental markers of reduced endothelial adherence of white cells.

The expertise of Dr Roth's surgical team ${ }^{1}$ is apparent, with no intra-aortic balloon counterpulsations or deaths in high-risk patients. Their carefully defined data characterize the advantages of white blood cell reduction in patients with ejection fractions of about $20 \%$, through reduced needs for dopamine, absent

From the Department of Cardiothoracic Surgery, University of California at Los Angeles Medical Center, Los Angeles, Calif.

Received for publication July 13, 2000; accepted for publication July 13, 2000.

Address for reprints: Gerald D. Buckberg, MD, Department of Cardiothoracic Surgery, UCLA Medical Center, Rm 62-258 CHS, Box 951741, Los Angeles, CA 90095-1741.

J Thorac Cardiovasc Surg 2000;120;640-1

Copyright (c) 2000 by The American Association for Thoracic Surgery

0022-5223/2000 $\$ 12.00+0 \quad \mathbf{1 2 / 1 / 1 1 0 1 7 4}$

doi: $10.1067 / \mathrm{mtc} .2000 .110174$ enoxamine for hemodynamic support, raised ejection fraction, diminished troponin release (a myocardial marker of cellular injury), less ventricular fibrillation after aortic unclamping (presumably from improved excitation/contraction coupling), and, finally, shorter intensive care unit stay (48 vs 60 hours), even though the last variant is not significant due to increased vulnerability. These aforementioned "soft or surrogate" end points conform precisely to their referenced reports of benefits of leukocyte depletion in damaged hearts. Conversely, no benefit of leukocyte depletion has been established in patients with an ejection fraction of more than $40 \%$.

The merits of cardiac versus systemic leukocyte depletion are clear, since systemic doses allowed only $38 \%$ reduction at the time of aortic unclamping. The white cell filter becomes less functional after more than $1000 \mathrm{~mL}$ blood delivery, so that selection of one versus two white blood filters becomes dependent on defining the role of leukocyte depletion throughout all periods of cold blood cardioplegia during aortic clamping, and/or only in the warm 500- to 700-mL reperfusate.

Surgical reperfusion strategies become confusing to our basic science and cardiology colleagues, who address single events after short ischemic intervals, whereas we confront prolonged ischemia for surgical repair. Unidimensional focus on one element will not be successful because ischemia unmasks many changes. Our study, quoted in the reference list, ${ }^{2}$ showed that white blood cell depletion alone reduced reperfusion injury but failed to restore contractility unless leukocyte depletion supplemented a more complex cardioplegic approach. The composite approach is clear from this study, since their blood cardioplegic solutions contain potassium, glucose, citrate, and a buffer with good clinical results, even without white blood cell depletion. ${ }^{1}$

We must establish cardiac surgical recognition of global endothelial stunning and develop efforts to reduce this injury during myocardial protection. In damaged hearts, conventional cardioplegic solutions can completely prevent myocyte injury, yet allow endothelial damage with resultant white blood cell adherence. ${ }^{3}$ A principal underlying mechanism is endothelial loss of nitric oxide production, subsequently allowing the neutrophil and platelet adherence 
and changing vasoactivity to impair subsequent vasodilatation. White blood cell adhesion is only one step in this injury.

Our principal surgical dilemma relates both to dealing with global stunning and understanding why this occurs. The neutrophil filter addresses the lesions after they are present, with acceptance that brief reperfusion interventions can reduce endothelial injury. Studies that focus on maintaining the intrinsic endothelium-dependent protective component, nitric oxide generation, may be useful. Hiramatsu, ${ }^{4}$ Mizuno, ${ }^{3}$ Kronon, ${ }^{5}$ and their colleagues, discovered that delivery of the natural nitric oxide precursor, Larginine, limits endothelial and myocyte damage, even without white blood cell depletion. Consequently, leukocyte depletion adds to the expanding catalog of strategies for surgical correction, but efforts at preventing endothelial stunning, rather than treating the injury, must be considered in the future.

\section{REFERENCES}

1. Roth M, Kraus B, Scheffold T, Reuthebuch O, Klövekorn W, Bauer EP. The effect of leukocyte-depleted blood cardioplegia in patients with severe left ventricular dysfunction: a randomized, double-blind study. J Thorac Cardiovasc Surg 2000;120:642-50.

2. Kofsky ER, Julia BL, Buckberg GD, Quillen JA, Acar C. Studies of controlled reperfusion after ischemia. XXII. Reperfusate composition: effects of leukocyte depletion of blood and blood cardioplegic reperfusates after acute coronary occlusion. J Thorac Cardiovasc Surg 1991;101:350-9.

3. Mizuno A, Baretti R, Buckberg GD, Young H, Vinten-Johansen J, $\mathrm{Ma} \mathrm{X}$, et al. Endothelial stunning and myocyte recovery after reperfusion of jeopardized muscle: a role of L-arginine blood cardioplegia. J Thorac Cardiovasc Surg 1997;113:379-89.

4. Hiramatsu T, Forbess J, Miura T, Nomura F, Mayer JE Jr. Additive effects of L-arginine infusion and leukocyte depletion on recovery after hypothermic ischemia in neonatal lamb hearts. $\mathrm{J}$ Thorac Cardiovasc Surg 1995;110:172-9.

5. Kronon MT, Allen BS, Halldorsson A, Rahman S, Wang T, Ilbawi $\mathrm{M}$. Dose dependency of L-arginine in neonatal myocardial protection: the nitric oxide paradox. J Thorac Cardiovasc Surg 1999;118:655-64.

\section{Availability of Journal back issues}

As a service to our subscribers, copies of back issues of The Journal of Thoracic and Cardiovascular Surgery for the preceding 5 years are maintained and are available for purchase from Mosby until inventory is depleted. The following quantity discounts are available: $25 \%$ off on quantities of 12 to 23, and one third off on quantities of 24 or more. Please write to Mosby, Subscription Customer Service, 6277 Sea Harbor Dr, Orlando, FL 32877, or call 800-654-2452 or 407-345-4000 for information on availability of particular issues and prices. If unavailable from the publisher, photocopies of complete issues may be purchased from Bell \& Howell Information and Learning, 300 N Zeeb Rd, Ann Arbor, MI 48106-1346; 734-761-4700 or 800-521-0600. 